\title{
Intervention Proposal for Infant Prognathism: A Case Report in a Non-Syndromic Pediatric Patient
}

\author{
Silvia J. Chedid ${ }^{* 1}$, Renata Húngaro ${ }^{2}$ \\ ${ }^{1}$ School of Dentistry, São Paulo Association of Dental Surgeons, São Paulo, São Paulo, 12240-490, Brazil \\ ${ }^{2}$ Specialization and Post-Graduation Program in Oral Motricity, Center of Specilization in Clinical Speech Therapy, \\ São Paulo, São Paulo, 01246-903, Brazil
}

*Corresponding author: Silvia J. Chedid; chedidsj@ gmail.com

Received 30 October 2021;

Accepted 13 November 2021;

Published 15 November 2021

\begin{abstract}
Treating Class III malocclusions has been presently considered one of the most challenging and complex interventions of orthodontic daily practice. In this study, we report a case of a 17-month-old female patient, initially diagnosed with Angle Class III malocclusion, mandibular protrusion, and without genetic syndromes. Upon initial admission at the dental office, patient's parents reported an inadequate bite pattern while the patient tried to eat solid food. Upon dental examination, a negative overjet of 8 millimeters was noticed and a two-phased treatment plan was established: 1. Performance of functional exercises; 2. Implementation of protractor device associated with masticatory guidance exercises. Radiographic examination and cephalometric analyses were performed throughout the case follow-up. Overall, the digital compression protocol carried out reverted the primary mandibular protrusion of -8 millimeters to +1 millimeters overbite, during the 6 months of treatment. In addition, the use of premaxillary protractor appliance increased the overbite to +2 millimeters. The patient responded satisfactory to the treatment plan performed, and after 2 years, a proper primary occlusion, oral functionality, and facial aesthetics were improved.
\end{abstract}

Keywords: Malocclusion; Prognathism, Pediatrics, Odontopediatrics, Orthodontics.

\section{Introduction}

Class III malocclusion is one of the most prevalent occlusal conditions worldwide (prevalence ranging from $1 \%$ to $20 \%$ ), and its etiology has been associated with multiple factors, including genetic and environmental factors ${ }^{[1-4]}$. For instance, an inappropriate postural habit of the mandible and an inadequate tongue posture might pathologically modify the mandibular condyle positioning within the glenoid fossa and consequently displace the correlated structures from the original position ${ }^{[5]}$. Furthermore, little chewing vigor, history of prolonged sucking habits, atypical swallowing, nasal airway obstruction, oral breathing, tongue size, enlarged tonsils, or presence of adenoids may also influence the existence and severity of Class III malocclusion ${ }^{[3,4]}$. In this context, the multidisciplinary team approach for identifying mouth breathing, airways obstruction, swallowing issues, and improper tongue and lips positioning at rest should be endorsed, especially among pediatrics patients. Therefore, the early recognition of etiological factors associated with malocclusions could positively interfere with factors involved in establishing a healthy primary occlusion, preventing future vertical, transversal, and anteroposterior pathologies ${ }^{[6]}$.

Over the last years, some orthodontic devices (i.e., Castillo Moralles) and sensory-motor manipulation protocols have become popular due to their effective results in the tongue and lips seal posture among Down Syndrome infant patients ${ }^{[7]}$. Frequently, these orthodontic therapies for non-syndromic individuals are performed in a later life stage ( $>6$ years of age), when the misalignment of the stomatognathic system has been already established and more difficult to intervene. Considering the early treatment, other authors have also suggested alternative appliances to reposition the mandible, including using a spatula behind the anterior maxillary teeth and in front of the anterior mandibular teeth to reposition the mandible distally and lower the tongue ${ }^{[8-11]}$. In addition, these techniques were added to posture exercises for the mandible when a postural mandibular protrusion was observed [8-11]. Notwithstanding, it is worthwhile mentioning that the beforementioned techniques designed to treat malocclusion during the permanent dentition are not appropriate as preventive interventions in children who are still in the eruption phase of primary dentition, neither for non-syndromic patients. Similarly, the available diagnostic resources used in mixed dentition are not suitable for infants. Thus, new parameters should be considered and advocated, especially for paediatric patients not previously diagnosed with genetic disorders.

Given the clinical relevance of this topic, this case report aimed to present several preventive interventions performed in a 17-month-old female patient diagnosed with Angle Class III 
mandibular protrusion without genetic syndromes. Delivered interventions include therapeutic massage techniques, digital compression exercises, and a device to stimulate maxillary growth. Furthermore, the patient underwent speech therapy treatment for lip tone, tongue posture, and masticatory guidance aiming at functional, postural, and maxillary growth stimuli.

\section{Materials and Methods}

A 17-month-old female patient reported to a private dental practice office in São Paulo (Brazil) with the chief complaint of mandible protrusion before the eruption of primary dentition (Figure 1A). According to the patient's parents, an inadequate bite pattern was noticeable when the infant tried to bite pieces of some solid food (including banana and apple) (Figure 1B and 1F). The patient's mother reported post-partum depression, no breastfeeding, and history of prognathism issues in her family, which potentially resulted in orthognathic surgery. At the initial consultation and examination, the patient was exclusively fed through bottle-feeding with a liquid and pasty diet and had four primary teeth erupted (5.1,6.1, 7.1, and 8.1 - as shown in Figure 1C and 1B). The female infant was born from unrelated parents at $371 / 7$ weeks of gestational age by caesarean section, with a birth weight of 2,950 kilograms and a five-minute Apgar score of 9. The patient's neonatal records showed negative screening for inborn errors of metabolism, as well as a normal human karyotype (46, XX).

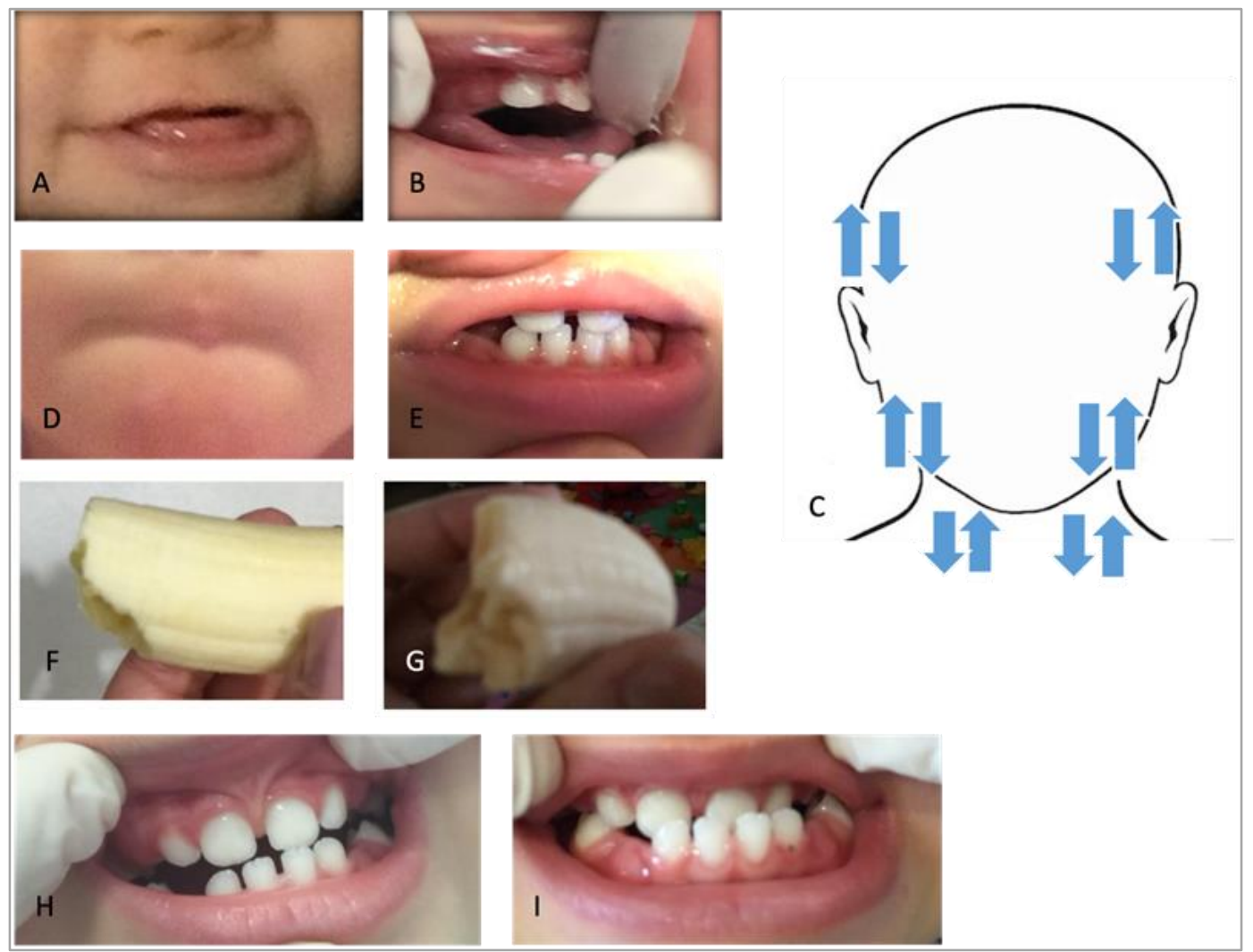

Figure 1: (A) Picture provided by the mother where the mandibular protrusion was already observed before the eruption of the primary teeth. (B) The first appointment, at the time the child presented $8 \mathrm{~mm}$ of a mandibular protrusion (August 4th, 2015). (C) Schematic drawing of the positioning and movements performed by hands and index, middle, ring, and little fingers. Slow movements up and down, bilateral, and simultaneously on the temporal, masseter, and hyoid muscles. (D) Banana bite before functional exercises. (E) Banana bite after functional movements. (F) Upper lip over the lower lip to reposition the mandible and to improve lip tonus (November 10th, 2015). (G) The occlusion with 1mm overjet after the 6-month treatment period (February 23rd, 2016). (I) Occlusal imbalance after the eruption of the first primary molar.

The diagnostic examination of differing skeletal from functional mandibular posture was carried out by manipulating the mandible to centric position and showed a negative overjet of 8 millimetres (similar to the reported while biting the banana) as observed in Figure 1B, 1C, and 1F. The patient presented with noncompromised nasal breathing throughout the clinical examination and had no non-nutritive sucking habits. In addition, based on the report from the otolaryngologist, the infant had no nasal airway obstruction and no hypertrophic tonsils/adenoids. However, according to the speech therapy evaluation, the infant had a lowered and protruded tongue position. There was no relevant medical history for the reported patient.

The orthodontic intervention was performed in two phases, as described below.

\subsection{First Treatment Phase}

At the beginning of the treatment phase, we have initially decided to perform functional exercises as an adapted protocol used for Trisomy 21 paediatric patients ${ }^{[7-9]}$. All procedures were demonstrated to the patient's mother during the first dental appointment, and the functional exercises were repeated three times under professional supervision to guarantee proper procedure execution. In addition, we advised the domestic deployment of exercises two to three times a day, for three to five minutes, depending on the child's collaboration. The practices were followed up once a week at the dental office.

The mother was instructed to maintain the infant's head supported on her lap in a 12 o'clock position with the child placed on a kneeto-knee position (directly ahead) to stabilize the child better ${ }^{[12]}$. The child's head was then stabilized on her legs, and with her 
hands bilaterally touching the child's face, muscle relaxation exercises were initiated (Figure 1C). Furthermore, digital compression exercises were subsequently executed to prompt premaxilla growth stimulus and mandibular retrusion ${ }^{[7-9,13]}$. The patient's position was constantly monitored and adapted throughout the procedure. A comprehensive step-by-step home-based guide associated with the relaxation exercises (extraoral muscle stretching) and exercises to stimulate premaxillary growth and mandibular posture is shown in Appendix I. These orthodontic procedures were performed from August 05, 2015, to January 12, 2016, until a harmonious relationship between the dental arches and improvement of the mandibular posture was achieved ${ }^{[7-9,12]}$. At the end of this period, the eight millimetres discrepancy between the dental arches was corrected to a one-millimetre overjet (Figure 1E). Moreover, as observed in Figure 1G, there was a remarkable improvement in the mandibular protrusion pattern based on the bite impression.

\subsection{Second Treatment Phase}

Following the first treatment period, the first primary molars erupted. The eruptions did not coincide, which created a loss of reference for the occlusion and a transverse and anteroposterior imbalance (Figure 1H and 1I). The observed dental imbalance was corrected with a protraction device, followed by a dental impression assessment and the creation of an acrylic orthopaedic appliance cemented with glass ionomer cement (Figures 2A, 2B, 2C, and 2D). We used a modified Adams clamp for dental anchorage, and the premaxillary protraction was established with screw activation. The screw activation consisted of a one-quarterturn weekly, for two months, until the projection of the premaxilla was sufficient to uncross and result in an overjet of two millimetres (Figures $2 \mathbf{E}$ and $\mathbf{2 F}$ ). After two months of screw activation, the appliance was maintained for an additional one month for better stabilization. Monthly professional check-ups supervised the entire activation process. (Figure 2G, 2H, and 2I).
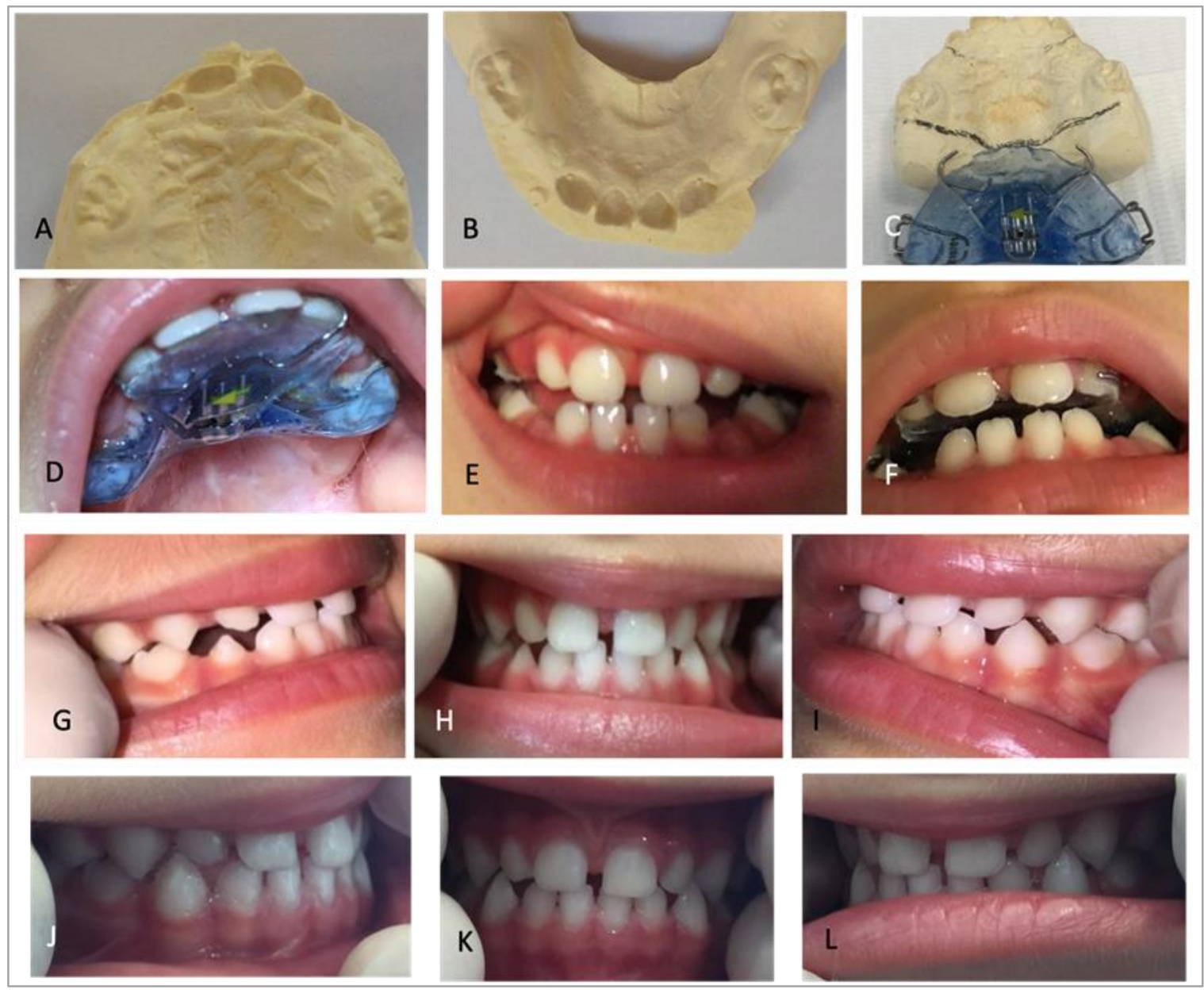

Figure 2: (A, B) Maxillary and mandibular plaster models. Note the first molars. Premaxilla protractor device with occlusal overlay, we can observe the modified Adams clamp device (April 27th, 2016). (C) Device cemented with glass ionomer cement. (D) The initial bite after installation of the device (April 27th, 2016). (E) The bite after two months of activations (June 6th, 2016). (F, G, H, I) Occlusion right after removing the premaxillary protraction device (after four months of treatment) (August, 10th, 2016). (J, K, L) Occlusion after six months of therapy with masticatory guidance, which we can observe an improved intercuspation of molars and canines.

After removing the protraction appliance (July 19, 2016), the patient initiated the masticatory orientation treatment with bilateral stimulus and molar intercuspation to stabilize the occlusion. It is worthwhile mentioning that the procedures above provided conditions to stabilize the position of the molars within the alveolar bone, avoiding the inclination by cross-contact. The masticatory orientation process required approximately six months to stabilize, so the function maintained the needed growth stimulus for the mandibular posture and coordinated bilateral chewing ${ }^{[14]}$. As far as the bilateral masticatory exercise is concerned, under the supervision of the speech therapist, the infant was invited to chew small pieces of apple wrapped in a thick paper tissue and was guided to perform bilateral chewing movements [14]. Simultaneously, she received manipulation for the distal positioning of the mandible for four months (Figure $\mathbf{2 J}, \mathbf{2 K}$, and 2L). Subsequently, the infant underwent speech therapy follow-up for tongue posture and phonemes. 


\subsection{Maintenance control}

The patient started to use a maxilla protraction appliance at night with fortnightly activations and a professional clinical assessment every three months. In December 2016, the first cephalometric assessment was performed (Figure 3A), while the second cephalometric evaluation occurred in August 2017 (Figure 3B).
The infant was monitored for the eruption of permanent dentition (Figures 4A, 4B, 4C, and 4D) and maintained regular speech therapy control for phonemes and monitoring of nasal breathing. Figures 3A1 and 3B1 show the treatment evolution of the cephalometric radiographs. The infant's parents were instructed to initiate postural therapy for cervical lordosis as soon as possible.

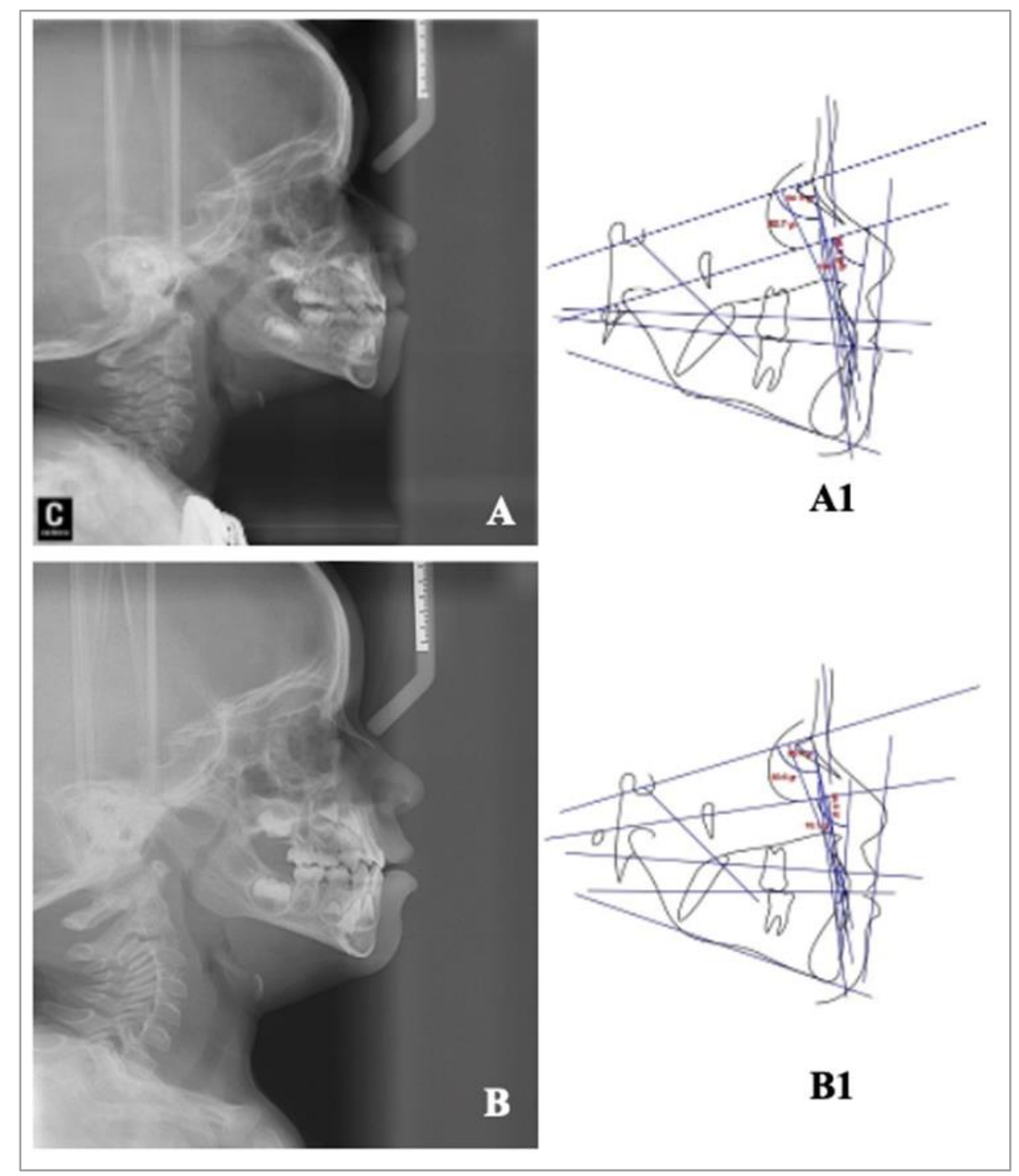

Figure 3: (A) First cephalometric radiograph in 2016, when the patient was two years and eight months old. (B) Second cephalometric radiograph performed in 2017.
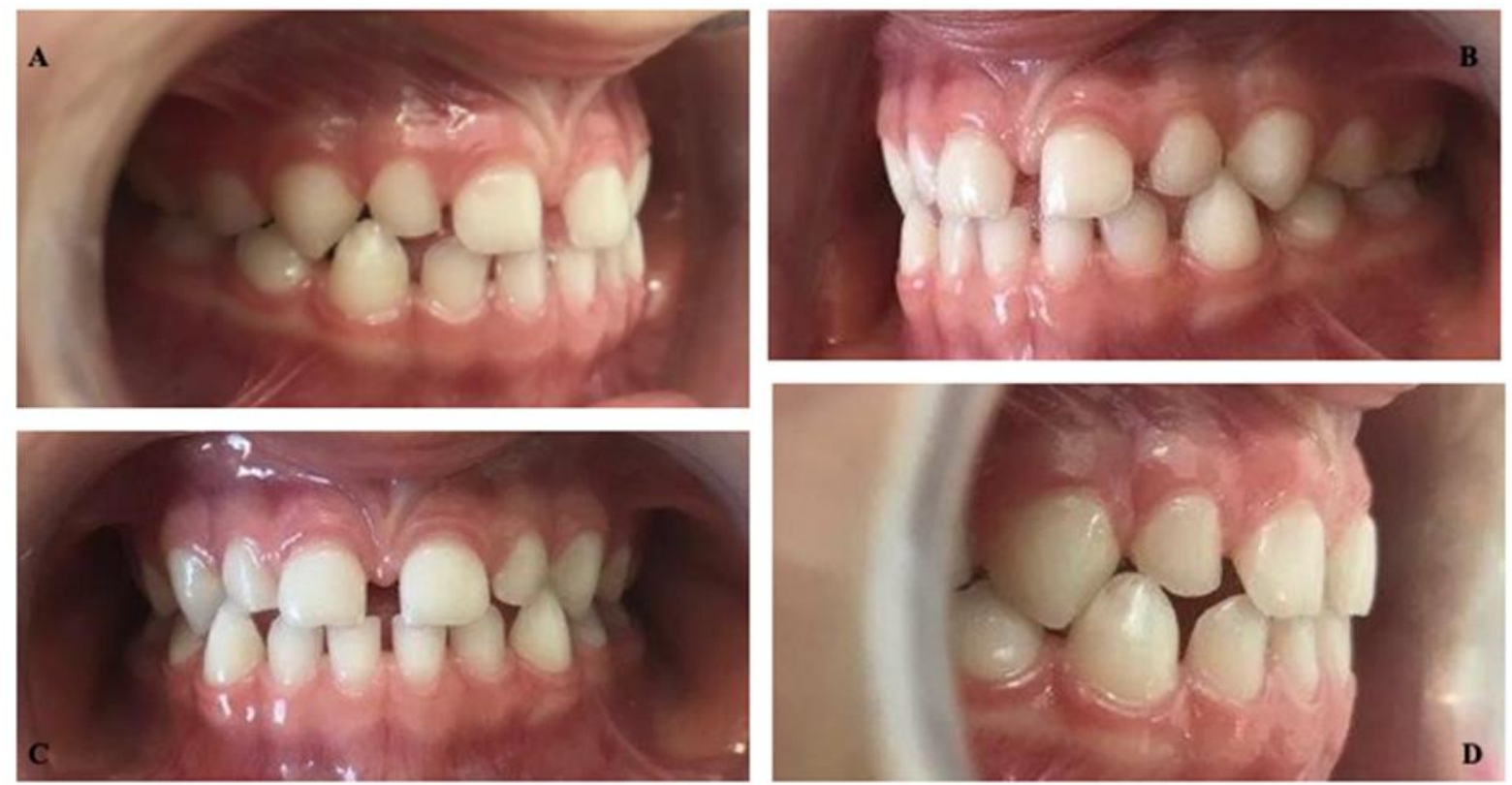

Figure 4: (A, B, C, and D) Stabilization of the patient's occlusion, which we can note the vertical position of incisors in their bone bases. 
Based on sequential cephalometric tracings analyses and the patient's current state, it can be evidenced that the infant's concave facial profile became convex, with improved facial balance and with the mandible maintaining a stable position. The ANB angle has remained relatively constant and close to two degrees since the first cephalometric analysis (registered ANB angle in 2016 was $2.20^{\circ}$ and in 2017 was $1.79^{\circ}$, as shown in Figures 3A1 and 3B1). The initially detected transverse imbalance was stable, and the anteroposterior relationship between the maxilla and the mandible also remained controlled, as shown in Figures 3A1 and 3B1. The cephalometric radiographs evidenced skeletal Class III malocclusion diagnosis, requiring further monitoring for potential orthopaedic or orthodontic dental interventions.

\section{Results and Discussion}

Correcting functional, dental, or skeletal facial disharmony during childhood is not yet a well-established standard dental practice, essentially because it involves several limitations. One of the biggest obstacles to delivering early orthodontic treatment for children is the requirement of infant collaboration and features associated with behaviour management. Furthermore, it requires specialized and qualified healthcare professionals and depends on parents' adherence to this complex treatment at the domestic level. In this case report of a non-syndromic paediatric patient, the involvement of both parents and dedication to the therapy was decisive for achieving highly effective results. Moreover, the timely clinical diagnosis of the significant orthodontic dysfunctions developed by the infant by an experienced dental specialist converted the initial maternal concern about future aesthetics and quality of life into more substantial treatment commitment for a long-term period ${ }^{[15-17]}$.

When the infant could not undergo conventional treatments, the massages and exercises performed at the initial treatment phase showed satisfactory results for establishing oral functions and achieving a harmonious relationship between the dental arches. Although the proposed exercises and digital compression for treating malocclusions are not novel therapies, there is still a shred of developing evidence that these techniques are effective for nonsyndromic patients ${ }^{[7-8,13]}$. Therefore, additional studies are needed because functional or skeletal dysfunctions which had not been treated during early childhood might be perpetuated in mixed and permanent dentition ${ }^{[6,14]}$. Additionally, it is noteworthy that delaying the delivery of orthodontic interventions may lead to more invasive, complex, long-lasting, and expensive orthodontic treatments in the future that can affect the patient's quality of life negatively ${ }^{[18]}$. For paediatric patients where no skeletal deformities are perceived but functional or postural impairments are detected, the orientation of the exercises might be even more effective if initiated in children's first years of life. This, as used as a preventive measure, provided the establishment of proper tongue and mandible posture, which may avoid several health issues in future skeletal patterns ${ }^{[8,19]}$. Thus, the prompt identification of any occlusal dysfunctions is advocated to achieve aesthetics and selfesteem outcomes and avoid more complex interventions during adulthood $^{[20]}$.

Based on the interceptive orthodontic treatment deployed, it was possible to observe a remarkable occlusal improvement in Class III malocclusion, as well as a positive reduction of the mandibular protrusion (initially measuring 8 millimetres between the maxillary and mandibular incisors). However, according to the extraoral and intraoral records, it is possible to observe that although there were a 2 millimetres overjet improvement, the molar relationship still evidence the Class III pattern. Therefore, the establishment of a harmonious bone and dentary growth condition was achieved. Nevertheless, it is worthwhile stressing that Class III malocclusions require a constant and long-term follow-up, even among patients who started with early orthodontic interventions, as these occlusal issues might relapse, especially in children in the craniofacial development phase ${ }^{[21-23]}$. In addition, we have observed a significant improvement between the anterior incisor's space and its vertical position in the bone bases. This can be associated with the proposal to use the premaxillary protraction appliance concomitant to the bilateral chewing exercises as they stimulate premaxilla growth. Furthermore, masticatory orientation contributed to the balance of its function and the establishment of more physiological occlusion.

The use of masticatory functional rehabilitation protocol in paediatric dentistry and the gradual introduction to difficult-tochew texture foods positively impacted the dental arches development. Proper chewing is fundamental in increasing food taste, safe-swallow process, optimal nutrient absorption, and a healthy, responsive digestive system ${ }^{[24,25]}$. Over the last years, several studies have evidenced that paediatric patients with a compromised chewing function were more likely to be malnourished than individuals with adequate chewing function ${ }^{[26-}$ ${ }^{28]}$. Thus, addressing malocclusions with comprehensive treatments and offering a resolution for mastication issues is vital for good health-related quality of life and to prevent systemic disorders. In addition, following our interventional protocol, the use of a patientdriven exercise for bilateral chewing and mandibular posture reinforced the masticatory guidance as it stabilized more adequately the occlusal apparatus ${ }^{[14,29]}$. Therefore, we firmly believe that if not treated promptly, the entire stomatognathic system of the patient would be altered for a prolonged period, which could potentially impact the masticatory functionality, nutrition, and quality of life.

Working in dental offices elsewhere with paediatric patients (especially children aging less than four years old) has been highly challenging. Mainly, taking photographs or obtaining plaster models of an infant's oral cavity is habitually a demanding task. The initial registration images of this clinical case report do not have proper quality mainly due to the difficulties in holding the patient in a steady position and the apparent lack of consciousness of understanding commands. Some recent studies have presented scans of the infant's oral cavity as a safer and easier technique for digital printing devices, specifically designed for infants with cleft lip syndromes (including Trisomy 21 and Pierre Robin syndrome) [29-31].

This case report has several strengths and features to be highlighted. Firstly, the relevance of the preventive intervention initiated in a non-syndromic paediatric patient relies on the achievement of symmetric and aesthetic craniofacial relationships, along with the maintenance of the mandible in a stable position. Secondly, as far as masticatory function is concerned, the infant's chewing performance significantly improved (alternating bilateral chewing movements). Lastly, but not least important, it is worth mentioning that all delivered interventions might minimize future interventions, affecting the patient's quality of life in a later life stage. One potential limitation of this case report relies upon its inherent methodological drawbacks - the low certainty of the evidence, as the study involves a single-reported case. Furthermore, the lack of ability to generalize, the danger of overinterpretation, and the impossibility to establish a cause-effect relationship might be evidenced as significant limitations. However, this case report is precious, mainly because it 
complements traditional orthodontic approaches and contributes to developing comprehensive literature about the early treatment of malocclusions. As the quality of evidence regarding the impact, effectiveness, and safety of early interventions in preventing malocclusions is still low, future clinical studies should be encouraged. These further studies should enrol larger patients' groups, with well-defined diagnostic criteria, rigorous scientific methodologies, and long-term control outcomes, in order to elucidate the complex ${ }^{[1,32]}$.

\section{Conclusions}

This clinical case report of an early orthodontic intervention, based on the combination of orthopaedic techniques with speech therapy protocols, had a positive result for establishing primary occlusion, oral functions, and facial aesthetics.

\section{Ethics approval and consent to participate}

Parents' consent was obtained in order to make this manuscript public.

\section{Conflicts of Interest}

The authors declare that there is no conflict of interest regarding the publication of this paper.

\section{Funding Statement}

None to be declared.

\section{Authors' contributions}

SJC and RH analyzed, obtained, interpreted, and wrote the initial and final version of this manuscript. All authors read and approved the final manuscript.

\section{Acknowledgments}

None to be declared.

\section{References}

[1] Alhammadi MS, Halboub E, Fayed MS, et al. Global distribution of malocclusion traits: A systematic review [published correction appears in Dental Press J Orthod. 2019 August 01;24(3):113]. Dental Press J Orthod. 2018;23(6):40.e1-40.e10. doi:10.1590/21776709.23.6.40.e1-10.onl

[2] Woon SC, Thiruvenkatachari B. Early orthodontic treatment for Class III malocclusion: A systematic review and meta-analysis. Am J Orthod Dentofacial Orthop. 2017 Jan;151(1):28-52. doi: 10.1016/j.ajodo.2016.07.017.

[3] Rongo R, D'Antò V, Bucci R, et al.Skeletal and dental effects of Class III orthopaedic treatment: a systematic review and meta-analysis. J Oral Rehabil. 2017 Jul;44(7):545-562. doi: 10.1111/joor.12495. Epub 2017 March 30.

[4] Grippaudo MM, Quinzi V, Manai A, et al. Orthodontic treatment need and timing: Assessment of evolutive malocclusion conditions and associated risk factors. Eur
J Paediatr Dent. 2020 Sep;21(3):203-208. doi: 10.23804/ejpd.2020.21.03.09.

[5] Zere E, Chaudhari PK, Sharan J, Dhingra K, Tiwari N. Developing Class III malocclusions: challenges and solutions. Clin CosmetInvestig Dent. 2018;10:99-116. Published 2018 June 22. doi:10.2147/CCIDE.S134303

[6] Peres KG, Peres MA, Thomson WM, Broadbent J, Hallal PC, Menezes AB. Deciduous-dentition malocclusion predicts orthodontic treatment needs later: findings from a population-based birth cohort study. Am J Orthod Dentofacial Orthop. 2015 Apr;147(4):492-8. doi:10.1016/j.ajodo.2014.12.019.

[7] Catillo-Morales R.; Avalle C.; Schimdt R. Possibilittà di tratamento della patologia orofaciale nelle sindrome di Down com la placa di regolalazione motoria. Rev PediatrPreventivaSociale. v. 34, p. 1-4, 1984.

[8] Camargo, MCF. Programa preventivo de maloclusiones en los bebés. In: FELLER, C. \& GONÇALVES, E.A.N. Actualización em Clinica dental. São Paulo: Artes Médicas, 1998, cap. 17, 405-42

[9] Roulet CP, Chedid SJ, Correa FNP, Correa MSNP. Orientações Básicas e Propostas de Intervenção na Dentição Decídua. In: Ortopedia e Ortodontia para a Dentição Decídua. Atendimento Integral ao Desenvolvimento Infantil. Chedid SJ - São Paulo. Ed. Santos, 2013. P223-241.

[10] Martinelli RLC, Marchesan IQ, Berretin-Felix. Posição da língua no repouso em bebês com e sem alteração do frênulo lingual. Anais do $22^{\circ}$ Congresso Brasileiro de Fonoaudiologia. 2014. p.5157. [acessoem: 2017 fev. 19]. Disponível em: http://sbfa.org.br/portal/anais2014/trabalhos_exp_select. php?tp=P\&id_artigo $=5157$

[11] Vadiakas G, Viazis AD. Anterior crossbite correction in the early deciduous dentition. Am J Orthod Dentofacial Orthop. 1992 Aug;102(2):160-2

[12] McDonald R, Avery D. Odontopediatria. 6 ed. Rio de Janeiro: Guanabara-Koogan. 1995. p.608.

[13] Lemes EF, Silva THMM, Correr AMA, Almeida EOC, Luchesi KF. Estimulação sensoriomotora intra e extraoral em neonatos prematuros: revisão bibliográfica. Rev. CEFAC [Internet]. 2015 Jun [citado 2021 Jan 04];17(3):945-955. Available at: http://www.scielo.br/scielo.php?script=sci_arttext\&pid= S151618462015000300945\&lng=pt.

[14] Planas P. Reabilitação neuro-oclusal. $2^{\text {a }}$ ed, Medisi, Rio de Janeiro, 1997.

[15] de Sousa, Emerson Tavares; da Silva, Beatriz Feitosa; Maia, Fabiana Barros Marinho; Forte, Franklin Delano Soares; Sampaio, Fábio Correia (2016). Perception of children and mothers regarding dental aesthetics and orthodontic treatment need: a cross-sectional study. Progress in Orthodontics, 17(1), 37-. doi:10.1186/s40510-016-0149-6

[16] Abanto J, Carvalho TS, Mendes FM, Wanderley MT, Bonecker M, Raggio DP. Impact of oral diseases and disorders on oral health-related quality of life of preschool children. Community Dentistry and Oral Epidemiology, v. 39, n. 2, p. 105-114, 2011.

[17] Aldrigui J M, Abanto J, Carvalho TS, Mendes FM, Wanderley MT, Bonecker M, Raggio DP. Impact of traumatic dental injuries and malocclusions on quality of 
life of young children. Health and Quality of Life Outcomes, v. 9, n. 1, p. 78, 2011

[18] Zhou Y, Wang Y, Wang X, Volière G, Hu R. The impact of orthodontic treatment on the quality of life a systematic review. BMC Oral Health. 2014 June 10;14:66. doi: 10.1186/1472-6831-14-66.

[19] Iodice G, Danzi G, Cimino R, Paduano S, Michelotti A. Association between posterior crossbite, skeletal, and muscle asymmetry: a systematic review.Eur J Orthod. 2016 Dec;38(6):638-651. Epub 2016 January 28.

[20] Gribel MN. Tratamento de mordidas cruzadas unilaterais posteriores com desvio postural mandibular com pistas diretas planas / Planas direct tracks in the treatment of unilateral crossbite with mandibular postural deviation. Rev. Dent.Pressortodon.ortop.maxilar;45(5):47-54,set.out.1999.

[21] Battagel JM. Predictors of relapse in orthodonticallytreated Class III malocclusions. Br J Orthod. 1994 Feb;21(1):1-13. doi: 10.1179/bjo.21.1.1. PMID: 8199158.

[22] 22.Yoshida I, Yamaguchi N, Mizoguchi I. Prediction of post-treatment outcome after combined treatment with maxillary protraction and chincap appliances. Eur $\mathrm{J}$ Orthod. 2006;28(1):89-96.

[23] Valerio P, Poklepovic-Pericic T, Rossi A, Grippaudo C, Campos JST, Borges do Nascimento IJ. The effectiveness of early interventions on malocclusion and its impact on craniofacial growth: a systematic review. Contemp Pediatr Dent. 2021:0(0):1-18. Doi: 10.51463/cpd.2021.61

[24] Mosca AC, Feron G, Chen J. Saliva and Food Oral Processing. J Texture Stud. 2019 Feb;50(1):4-5. doi: 10.1111/jtxs.12389. PMID: 30724363.

[25] van der Bilt A, Engelen L, Pereira LJ, van der Glas HW, Abbink JH. Oral physiology and mastication. PhysiolBehav. 2006 August 30;89(1):22-7. doi: 10.1016/j.physbeh.2006.01.025. Epub 2006 March 29. PMID: 16564557.

[26] Watson S, McGowan L, McCrum LA, Cardwell CR, McGuinness B, Moore C, Woodside JV, McKenna G. The impact of dental status on perceived ability to eat certain foods and nutrient intakes in older adults: crosssectional analysis of the UK National Diet and Nutrition Survey 2008-2014. Int J BehavNutr Phys Act. 2019 May 14;16(1):43. doi: 10.1186/s12966-019-0803-8. PMID: 31088468; PMCID: PMC6518671.

[27] Sheiham A, Steele J. Does the condition of the mouth and teeth affect the ability to eat certain foods, nutrient and dietary intake and nutritional status amongst older people? Public Health Nutr. 2001 Jun;4(3):797-803. doi: 10.1079/phn2000116. PMID: 11415487.

[28] Almotairy N, Kumar A, Grigoriadis A. Effect of food hardness on chewing behavior in children. Clin Oral
Investig. $2021 \quad$ Mar;25(3):1203-1216. doi: 10.1007/s00784-020-03425-y. Epub 2020 June 29. PMID: 32613432; PMCID: PMC7878268.

[29] Bäckman B, Grevér-Sjölander AC, Bengtsson K, Persson J, Johansson I. Children with Down syndrome: oral development and morphology after use of palatal plates between 6 and 48 months of age. Int J Paediatr Dent. 2007 Jan;17(1):19-28. doi: 10.1111/j.1365263X.2006.00781.x.

[30] Xepapadeas AB, Weise C, Frank K, Spintzyk S, Poets CF, Wiechers C, Arand J, Koos B.BMC Oral Health. Technical note on introducing a digital workflow for newborns with craniofacial anomalies based on intraoral scans - part I: 3D printed and milled palatal stimulation plate for trisomy 21. 2020 January 23;20(1):20. doi: 10.1186/s12903-020-1001-4.

[31] Xepapadeas AB, Weise C, Frank K, Spintzyk S, Poets CF, Wiechers C, Arand J, Koos B. Technical note on introducing a digital workflow for newborns with craniofacial anomalies based on intraoral scans - part II: 3D printed Tübingen palatal plate prototype for newborns with Robin sequence. BMC Oral Health. 2020 June 16;20(1):171. doi: 10.1186/s12903-020-01159-7.

[32] Harrison, JE, Ashby D. Orthodontic Treatment for Posterior Crossbites. Cochrane database of Systematic Reviews, Issue 4, 2013. DOI: 10.1002/14651858.CD000979.PUB4

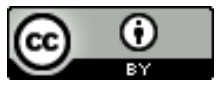

Open Access This article is licensed under a Creative Commons Attribution 4.0 International License, which permits use, sharing, adaptation, distribution and reproduction in any medium or format, as long as you give appropriate credit to the original author(s) and the source, provide a link to the Creative Commons license, and indicate if changes were made. The images or other third party material in this article are included in the article's Creative Commons license, unless indicated otherwise in a credit line to the material. If material is not included in the article's Creative Commons license and your intended use is not permitted by statutory regulation or exceeds the permitted use, you will need to obtain permission directly from the copyright holder. To view a copy of this license, visit https://creativecommons.org/licenses/by/4.0/.

(C) The Author(s) 2021 